\title{
Phenotype to genotype using forward-genetic Mu-seq for identification and functional classification of maize mutants
}

\author{
Charles T. Hunter*, Masaharu Suzuki, Jonathan Saunders, Shan Wu, Alexander Tasi, \\ Donald R. McCarty and Karen E. Koch
}

Plant Molecular and Cellular Biology Program, Institute of Food and Agricultural Sciences, Horticultural Sciences, University of Florida, Gainesville, FL, USA

\section{Edited by:}

Shawn Kaeppler, University of

Wisconsin-Madison, USA

Reviewed by:

Karen McGinnis, Florida State University, USA

Rajandeep Sekhon, University of

Wisconsin-Madison, USA

Candice Hirsch, University of

Minnesota, USA

\section{*Correspondence:}

Charles T. Hunter, Horticultural

Sciences, University of Florida, 2550

Hull Rd., Gainesville, FL 32611, USA

e-mail: cthunter3@gmail.com
In pursuing our long-term goals of identifying causal genes for mutant phenotypes in maize, we have developed a new, phenotype-to-genotype approach for transposon-based resources, and used this to identify candidate genes that co-segregate with visible kernel mutants. The strategy incorporates a redesigned Mu-seq protocol (sequence-based, transposon mapping) for high-throughput identification of individual plants carrying $\mathrm{Mu}$ insertions. Forward-genetic Mu-seq also involves a genetic pipeline for generating families that segregate for mutants of interest, and grid designs for concurrent analysis of genotypes in multiple families. Critically, this approach not only eliminates gene-specific PCR genotyping, but also profiles all Mu-insertions in hundreds of individuals simultaneously. Here, we employ this scalable approach to study 12 families that showed Mendelian segregation of visible seed mutants. These families were analyzed in parallel, and 7 showed clear co-segregation between the selected phenotype and a Mu insertion in a specific gene. Results were confirmed by PCR. Mutant genes that associated with kernel phenotypes include those encoding: a new allele of Whirly1 (a transcription factor with high affinity for organellar and single-stranded DNA), a predicted splicing factor with a $\mathrm{KH}$ domain, a small protein with unknown function, a putative mitochondrial transcription-termination factor, and three proteins with pentatricopeptide repeat domains (predicted mitochondrial). Identification of such associations allows mutants to be prioritized for subsequent research based on their functional annotations. Forward-genetic Mu-seq also allows a systematic dissection of mutant classes with similar phenotypes. In the present work, a high proportion of kernel phenotypes were associated with mutations affecting organellar gene transcription and processing, highlighting the importance and non-redundance of genes controlling these aspects of seed development.

Keywords: forward genetics, mutator, transposon, sequencing, Mu-Seq, UniformMu

\section{INTRODUCTION}

Strategies for inducing and recovering insertional mutations are an important foundation of functional genomics. Model plant species for which there are public collections of mutants include Arabidopsis (Parinov et al., 1999; Tissier et al., 1999; Galbiati et al., 2000; Samson et al., 2002; Sessions et al., 2002; Alonso et al., 2003; Rosso et al., 2003; Kuromori et al., 2004; Woody et al., 2007), rice (Miyao et al., 2003; Jeong et al., 2006; Zhang et al., 2006; Hsing et al., 2007; Miyao et al., 2007; Krishnan et al., 2009), and maize (Bensen et al., 1995; Meeley and Briggs, 1995; Raizada and Walbot, 2000; Walbot, 2000; Cowperthwaite et al., 2002; May et al., 2003; Slotkin et al., 2003; Ahern et al., 2009; Vollbrecht et al., 2010; McCarty et al., 2013b). These reversegenetic resources have proven invaluable to investigations of gene functions. In particular, the UniformMu maize population (McCarty et al., 2005) is a public resource for insertional mutagenesis based on the Robertson's Mutator $(\mathrm{Mu})$ transposon (Robertson, 1978). The resource currently comprises over 8000 lines and 35,000 genic insertions that are accessible online (maizegdb.org; McCarty et al., 2005; Settles et al., 2007; McCarty et al., 2013a,b).
Use of insertion-based resources, whether for forward or reverse genetics, requires accurate and reliable approaches for tracking mutations. Typically, a small number of segregating F2 individuals from a UniformMu maize family (or from a similar resource) are genotyped by PCR for the presence/absence of a particular Mu insertion. Gene-specific PCR primers are required, as well as individual DNA extractions for each plant, and prior knowledge of sites for candidate gene insertions. While this approach has been employed effectively over the last two decades (Settles et al., 2007; Hunter et al., 2012; McCarty et al., 2013a,b), development and optimization of reliable, gene-specific, PCRgenotyping assays can be time-, labor-, and resource-intensive. The challenges include PCR-recalcitrant sequences, false positives, and inconsistent results. The value of a more efficient approach is especially clear when large numbers of insertions are being followed in multiple lines, particularly for high-copy transposon systems like that of Mutator.

Construction of the UniformMu resource has fostered development of high-throughput sequencing strategies that enable efficient mapping of new $\mathrm{Mu}$ insertions in the maize genome (Settles et al., 2007; McCarty et al., 2013a,b). The common goal 
of these approaches has been to amplify and sequence genomic DNA immediately flanking germinal $\mathrm{Mu}$ insertion sites in large numbers of maize plants. The most advanced of these sequencing methods, Mu-seq, specifically amplifies regions of DNA that extend from the highly-conserved, terminal inverted repeat (TIR) sequence of the Mu element into the immediately-adjacent sequence of the host genome (McCarty et al., 2013b). The key feature of this technology lies in its capacity to map thousands of $\mathrm{Mu}$ insertions precisely, and to do so concurrently in a large number of maize lines. Sequencing "reads" resulting from $\mathrm{Mu}-$ seq analysis have short regions of $\mathrm{Mu}$-TIR sequence that confirm their $\mathrm{Mu}$-anchored origin, followed by specific host sequences that flank $\mathrm{Mu}$ insertion sites. A comparison of these reads to the maize genome allows insertion sites to be mapped. Multiplexing is enabled by inclusion of a 4-base, sample-specific barcode that allows up to 64 DNA libraries to be sequenced in the same flow cell of an Illumina sequencer. The reliability of this method has been demonstrated during construction of the UniformMu resource for reverse genetics (McCarty et al., 2013b) and has been used to map novel Mu insertions to over 9000 specific maize lines.

Here we present forward-genetic $\mathrm{Mu}$-seq, a strategy designed for linking phenotypes with their causal, transposon mutations by taking high-throughput profiling of transposon insertions to the resolution of individual plants within arrangements of multiple, segregating families. The approach includes the genetic analyses involved in generating these families, and grid designs that incorporate genotype and phenotype. We use forward-genetic $\mathrm{Mu}$-seq to simultantously track the $\mathrm{Mu}$ elements in each plant and family and compare their presence with the expression of a given phenotype. Results allow co-segregation analyses to be conducted on a much larger scale (few to many concurrent families) and with vastly improved accuracy, time input, and cost effectiveness over PCR alone. In addition to the efficacy of this approach, we show the outcome of its use; a set of seed mutants linked with putative, causal genes. These data not only allow prioritization of mutants for subsequent study based on gene annotations, but also demonstrate how reverse-genetic $\mathrm{Mu}$-seq can be used to dissect a specific developmental pathway. We analyze the selected seed mutants with the goal of determining the specific developmental or physiological processes impaired in these similar mutants. Results presented here highlight the critical role of nuclear-encoded proteins that influence expression and transcript processing of organellar genes during maize kernel development. The capacity for systematic analysis of multiple mutants is especially important for genetic dissection of complex processes, such as seed formation, that involve a large number of loci.

\section{MATERIALS AND METHODS \\ PLANT MATERIAL, MATING STRATEGY, AND PHENOTYPING}

All maize lines used were selected from the publicly-available, UniformMu collection, based on the presence of a kernel phenotype. Plants were grown under field conditions at the UF-Plant Science Research Unit at Citra, FL and self-pollinated to check for heritability, as well as back-crossed to the wildtype, W22-inbred to generate F2 segregating progeny. Segregating progeny were also grown under field conditions and self-pollinated. Prior to pollination, leaf samples were collected for later use in construction of forward-genetics $\mathrm{Mu}$-seq grids. Ears from self-pollinated plants were scored for presence/absence of seed phenotypes. Kernels were imaged using a Leica MZ 125 dissecting microscope with an attached camera (Diagnostic Instruments, model 2.3.1).

\section{GRID CONSTRUCTION AND DNA EXTRACTION}

Figure 1B shows the construction strategy for a 12-by-12, forward-genetics $\mathrm{Mu}$-seq grid of kernel mutants. Leaf samples

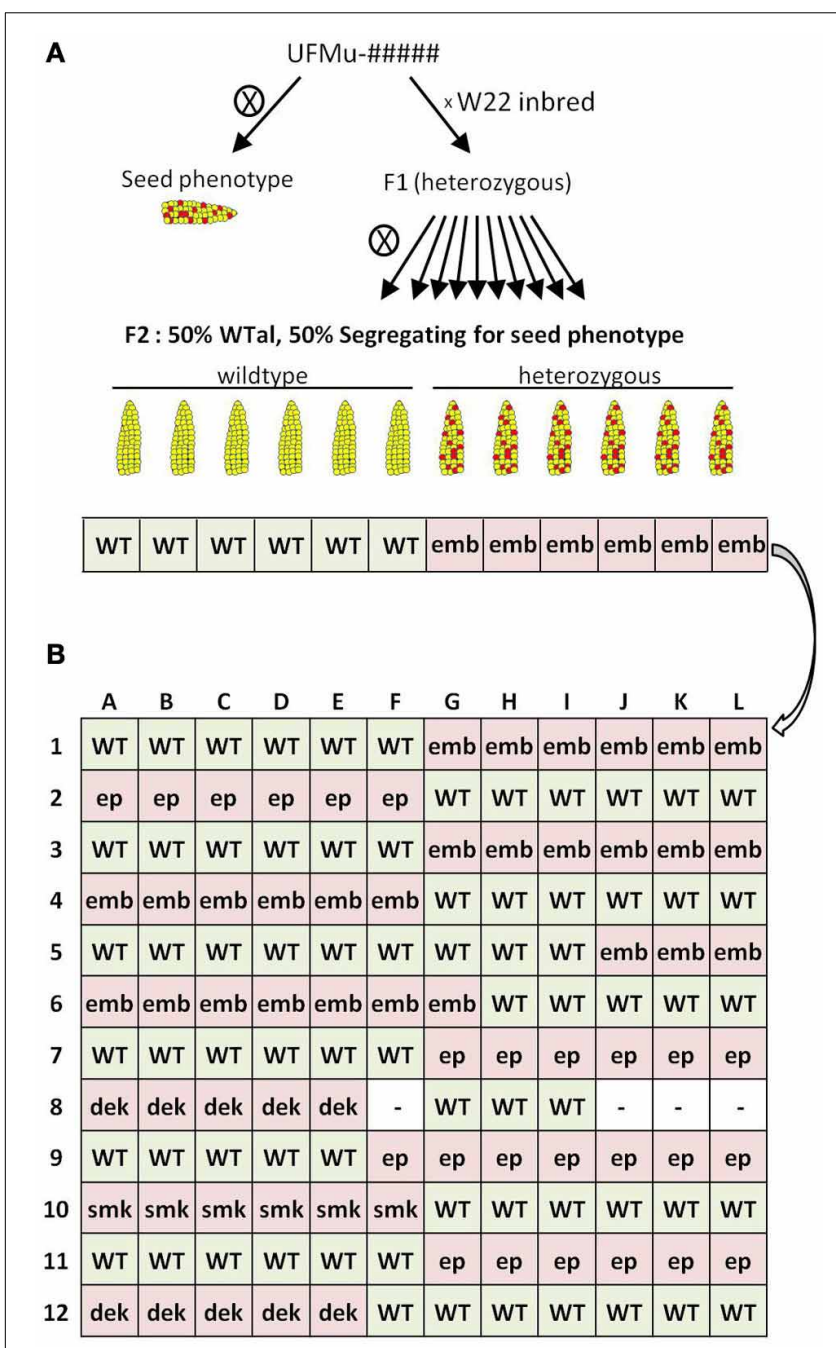

FIGURE 1 | Genetic strategy and grid design for forward-genetics Mu-seq. (A) UniformMu families segregating for seed phenotypes were selected for inclusion in the forward-genetics Mu-seq grid. For selected families, individuals were backcrossed to the W22 inbred, followed by selfing of the F1 progeny. Resulting ears were examined for the phenotype of interest, and scored as positive or negative. The expected ratio of ears with and without visible phenotypes was $50 \%$. (B) Leaf samples from mothers of the phenotyped ears were pooled according to the diagramed grid design, such that pools 1 through 12 represented twelve individuals from a single family, and pools $A$ through $L$ represented a single individual from each family. DNA was extracted from the resulting 24 pools of leaf samples, sequencing libraries were constructed with each pool being assigned a specific key-code identifier, and Mu flanks were sequenced using a single Illumina flow cell. Seed phenotype abbreviations: embryo lethal (emb), empty pericarp (ep), small kernel (smk), defective kernel (dek). 
were pooled based on family and plant number, so that individuals were represented once in each axis. Each of the 24 pools contained 12 leaf samples, and genomic DNA was extracted from each pool. Samples (about $10 \mathrm{~g}$ ) were ground in liquid nitrogen and frozen powder was added to $20 \mathrm{~mL}$ of extraction buffer $(42 \%$ Urea, $6 \% \mathrm{NaCl}[5 \mathrm{M}$ ], 5\% Tris-HCl [pH 8.0], 4\% EDTA [0.5 M], $1 \%$ Sarkosyl [Fisher Lot \# 101874]). Samples were allowed to thaw before addition of $5 \mathrm{~mL}$ phenol (Fisher Lot \# 116885) and $5 \mathrm{~mL}$ chloroform solution (24 part chloroform [Fisher Lot \# 066906], 1 part 3-methylbutanol [Sigma 19392-500ML]). Solutions were thoroughly mixed and transferred to $50-\mathrm{mL}$, Phase Lock gel tubes (Eppendorf Cat \# 06-443-18) for centrifugation at $4000 \mathrm{rpm}$ for $5 \mathrm{~min}$ in a Thermo Forma swinging-bucket centrifuge (model 5530 1LGP). Supernatant (about $5 \mathrm{~mL}$ ) was transferred to $14-\mathrm{mL}$ centrifuge tubes (Falcon 352059), and $5 \mathrm{~mL}$ of $3 \mathrm{M} \mathrm{NaOAc}(\mathrm{pH}$ 5.2) was added. After mixing gently, $20 \mathrm{~mL}$ of isopropanol was added to precipitate DNA, which was then removed by pipette tip, washed in $1 \mathrm{~mL}$ of $70 \%$ ethanol, gently mixed, and centrifuged for $5 \mathrm{~min}$ at $8000 \mathrm{rpm}$. Liquid was removed and pellets were allowed to air-dry before addition of $500 \mathrm{~mL}$ TE $(10 \mathrm{mM}$ Tris- $\mathrm{HCl}, 1 \mathrm{mM}$ EDTA, pH 8.0).

To remove RNA, $5 \mathrm{uL}$ Ribonuclease A solution $(1 \mathrm{mg} / \mathrm{mL}$ [Thermo Scientific Cat \# AB-0549]) was added was added to $250 \mathrm{~mL}$ of DNA. Solutions were incubated at $37^{\circ} \mathrm{C}$ for $20 \mathrm{~min}$ then transferred to ice. DNA was precipitated by adding $500 \mathrm{uL}$ of cold Ethanol (100\%) and $100 \mathrm{uL}$ of $5 \mathrm{M} \mathrm{NH}_{4}$ Ac. Tubes were centrifuged at 13,000 rpms for $5 \mathrm{~min}$, followed by removal of supernatant by pipetting. Pellets were washed with $500 \mathrm{uL}$ of $70 \%$ ethanol, and centrifuged at $13,000 \mathrm{rpm}$ for $5 \mathrm{~min}$. Supernatant was removed and pellets were allowed to dry before re-suspension in $100 \mathrm{uL}$ TE (10 mM Tris-HCl, $1 \mathrm{mM}$ EDTA, $\mathrm{pH}$ 8.0).

\section{SEOUENCING LIBRARY CONSTRUCTION}

Libraries for sequencing were prepared for each of the 24 pooled DNA samples as described in detail by McCarty et al. (2013b). Briefly, samples were sheared by sonication and size selected for an average size of $1 \mathrm{~kb}$. Blunt end ligation was used to add double stranded tiB (Roche Inc., GS FLX Titanium General Library Preparation Manual), that would serve as priming targets for PCR. To amplify Mu-flanking sequences, we used a touchdown, two-step PCR reaction using the Mu TIR-specific primer, TIR6 (Settles et al., 2007; Supplemental Figure 2), and the adapter-specific primer, tiB (McCarty et al., 2013b; Supplemental Figure 2). Two additional rounds of nested PCR were used to incorporate 4-base barcodes and Illumina sequencing adaptors (see McCarty et al., 2013b). Libraries were pooled and concentrated using a concentrator column to achieve a final concentration of over $10 \mathrm{nM}$ DNA. The combined library was sequenced in a single lane of an Illumina HiSeq II with unidirectional, 100-base sequencing.

\section{BIOINFORMATIC ANALYSIS}

Sequencing reads were screened for quality and trimmed as in McCarty et al. (2013b). Screens included analysis of overall sequencing quality, presence of a valid barcode, and inclusion of a complete TIR sequence. After barcode identifications were appended to the each read, the adapter and TIR sequences were trimmed. The remaining quality flanking sequences were used for precise mapping to the B73 reference genome by BLASTN (Altschul et al., 1990). Output from the alignment analyses were parsed into a custom database constructed using the Java Collections framework, described in McCarty et al. (2013b). The database output included chromosome positions and normalized read numbers for insertions identified in each of the 24 barcoded libraries (Supplemental Table 1). Normalization followed established protocols (McCarty et al., 2013b) to weight each sublibrary equally.

A cut-off of 50 sequencing reads for an individual sample was used to call the presence of an insertion. The forward-genetic $\mathrm{Mu}$-seq grid design allowed the presence or absence of each insertion to be resolved at the individual-plant level. Insertion locations and numbers of sequence reads flanking each of their sites were tabulated and arranged to visualize the genotypic status of each individual (Figure 2; Supplemental Table 1). The presence or absence of each insertion was compared to the distribution of mutant phenotypes in each family to test for co-segregation between them.

\section{VALIDATION OF CO-SEGREGATIONS USING PCR}

To further test such instances of co-segregation, larger families segregating for the mutant phenotype of interest were genotyped by PCR using gene-specific and Mu-TIR-specific primers. For each of the seven insertions found to co-segregate with a mutant phenotype, PCR primers were designed that flanked the insertion site (Fwd primer upstream of insertion and Rev primer downstream). Primers were designed with melting temperatures between 63 and $65^{\circ} \mathrm{C}$ using web-based tools available from Integrated DNA Technologies (idtdna.com). Primer sequences are provided in Supplemental Figure 2. Gene-specific primers were used to detect presence of a normal gene copy, whereas one gene-specific primer was used in combination with a $\mathrm{Mu}$ TIR-specific primer (TIR6) to detect the presence of an insertion. Reactions were run in an Eppendorf Mastercycler ProS thermocycler with the following parameters: $94^{\circ} \mathrm{C}$ for $5 \mathrm{~min}$, then 40 cycles at $94^{\circ} \mathrm{C}$ for $45 \mathrm{~s}, 60^{\circ} \mathrm{C}$ for $90 \mathrm{~s}, 72^{\circ} \mathrm{C}$ for $100 \mathrm{~s}$, then $72^{\circ} \mathrm{C}$ for $7 \mathrm{~min}$. Products were separated on $1 \%$ agarose gels to visualize and test for of co-segregation of mutant phenotypes with the presence of expected, amplified DNA fragments.

\section{LOCALIZATION PREDICTIONS}

Putative subcellular localizations were estimated using the webbased Target-P peptide prediction program (Emanuelsson et al., 2000, 2007). Predicted amino acid sequences for each putative, causal gene were obtained from maizesequence.org and analyzed using TargetP criteria for plant proteins with all parameters at their default settings. TargetP scores above. 700 were considered predictive of organellar targeting.

\section{RESULTS}

To explore the potential of using forward-genetic $\mathrm{Mu}$-seq for systematic analysis of maize mutants, we selected 12 families with visible-seed phenotypes identified in a screen of the UniformMu transposon population. We opted to use seed mutants due to our long-standing interest in kernel development (McCarty et al., 


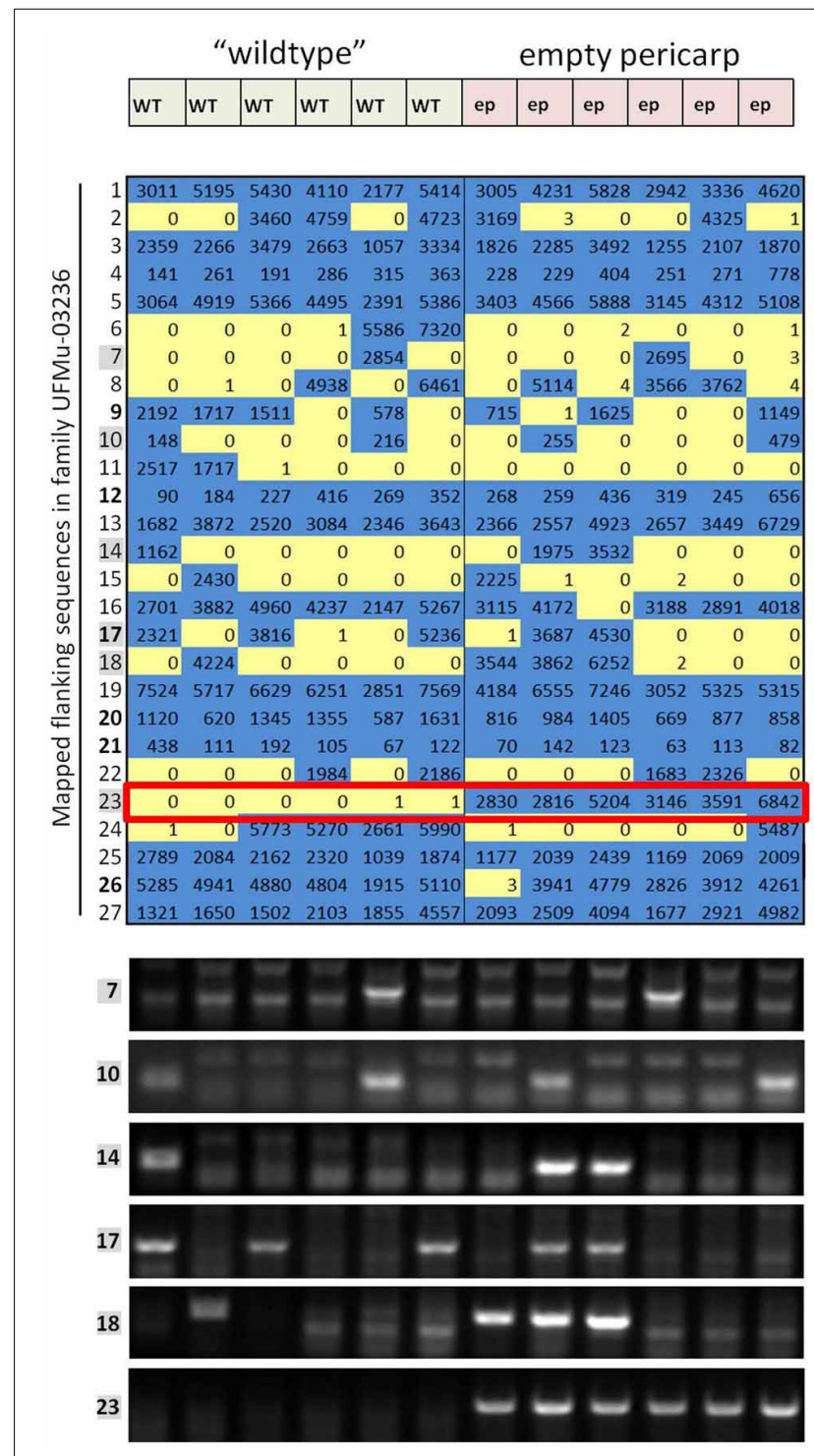

FIGURE 2 | Expanded results for one of the families in the forward-genetics Mu-seq grid. Sequencing reads obtained for pool-7, corresponding to family UFMu-03236, are organized here based on insertion site (chromosome and location) and compared to phenotypic data to test co-segregation. In this example, normal ears made up the left half of the grid (pools $A$ through $F$ ) and mutant ears were arranged on the right side of the grid (pools $G$ through $L$, see Figure 1B). Of the 27 flanking sequences identified in pool 7 (assigned to family UFMu-03236), only number 23 showed co-segregation with the empty-pericarp phenotype (outlined in red). To check the consistency and reliability of the sequencing approach, including assignment of map locations, DNA from the individual plants included in the grid for this family was analyzed by PCR for the presence/absence of six of the segregating insertions (indicated by gray boxes). Results were consistent for PCR and sequencing.

1991; McCarty, 1995; Andersen et al., 2002; Koch, 2004), the importance of these structures to humankind (Klopfenstein et al., 2012; Ray et al., 2012), and also because seed mutants represent a large, genetically-complex, phenotypic class. Our first step in developing a forward-genetic strategy was to implement a multi-generation, genetic pipeline that (1) tested whether phenotypes were recessive and heritable, (2) established segregating, backcross families that were suitable for linkage analysis, and (3) provided materials for phenotypic investigation and classification.

\section{GENETIC STRATEGY AND SEOUENCING GRID DESIGN}

The 12 families selected for analysis in the present study were characterized using the genetic strategy outlined in Figure 1A. This included selfing each putative heterozygous mutant plant to test for heritable phenotypes and concurrently back-crossing these individuals to W22-inbred females. Where phenotypes were heritable, F1 progeny of the backcrosses were selfed and the resulting ears were scored as segregating or non-segregating relative to the mutant phenotypes. For each mutant family, DNA from mothers of six segregating ears (heterozygous individuals) and six normal ears (homozygous individuals) were selected for inclusion in a forward-genetic Mu-seq grid. Balanced numbers of heterozygous and homozygous-normal individuals were not essential for this approach, therefore in cases where ears of either class (mutant or normal) were limited in number, then individuals from the other class were used in the grid (Figure 1B). The resulting 12-by-12 array of DNA from individuals bearing ears is diagramed in Figure 1B. The grid design was arranged to simplify interpretation of resulting sequence data by grouping mutant and non-segregating ears on the left or right side of the grid, alternating by family. Leaf samples had been collected from the parent plant of each ear and were pooled as shown in Figure 1B. The DNA for analyses was extracted from each of these 24 pools. Resulting DNA samples were each assigned a unique barcode (attached during construction of sequencing libraries) and sequenced together in a single Illumina flow cell (McCarty et al., 2013b).

\section{ANALYSIS OF SEOUENCING GRID RESULTS}

In total, 341 unique, genic insertions (as determined by greater than 100 normalized sequencing read counts in the familyspecific pool fraction) were identified and mapped in the twelve Uniform Mu families included in this forward-genetic $\mathrm{Mu}-\mathrm{seq}$ grid (Table 1). Out of these, 290 insertions were present in multiple plants and thus confirmed as germinal mutations. The remaining 51 insertions were identified in single plants among twelve individuals within single families. The prevalence of rare insertions in one family (UFMu-04889, with 48 of 115 total insertions) is consistent with the presence of residual transposase activity in this line. Although genetic selection is used to limit transposase activity in plants prior to $\mathrm{Mu}$-seq analysis, residual MuDR-activity is detected in about $1 \%$ of UniformMu lines (McCarty et al., 2013b). Because of the deep-sequence coverage obtained by forward-genetic $\mathrm{Mu}$-seq, such single-plant insertions (whether from germinal or somatic transposition events) can be readily distinguished from segregating germinal insertions as above.

Results from this forward-genetic $\mathrm{Mu}$-seq grid (and others arranged as in Figure 1) can be readily interpreted as in Figure 2. Sequencing reads are parsed by barcode, trimmed, aligned to the maize reference genome, and assigned map locations as described in McCarty et al. (2013b). The process is further streamlined 
Table 1 | Sequencing results from forward-genetics Mu-seq grid.

\begin{tabular}{|c|c|c|c|c|c|c|}
\hline Pool & Family & Phenotype & $\begin{array}{l}\text { Genic } \\
\text { insertions }\end{array}$ & $\begin{array}{l}\text { Segregating } \\
\text { insertions }\end{array}$ & $\begin{array}{l}\text { Single-plant } \\
\text { insertions }\end{array}$ & $\begin{array}{l}\text { Positive } \\
\text { co-segregation }\end{array}$ \\
\hline 1 & UFMu-00469 & emb & 33 & 33 & 0 & 1 \\
\hline 3 & UFMu-04889 & smk/emb & 115 & 67 & 48 & 1 \\
\hline 4 & UFMu-03275 & dek/emb & 11 & 10 & 1 & 1 \\
\hline 7 & UFMu-03236 & ep & 27 & 27 & 0 & 1 \\
\hline 8 & UFMu-01057 & dek & 7 & 7 & 0 & 0 \\
\hline 9 & UFMu-00298 & ep & 26 & 26 & 0 & 1 \\
\hline 10 & UFMu-05297 & smk & 8 & 8 & 0 & 1 \\
\hline 11 & UFMu-03318 & ep & 4 & 4 & 0 & 0 \\
\hline
\end{tabular}

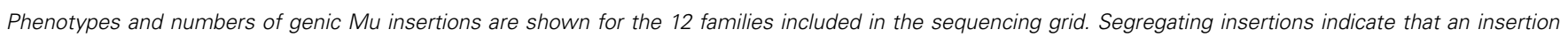

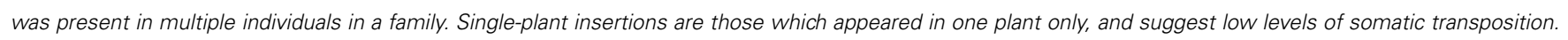

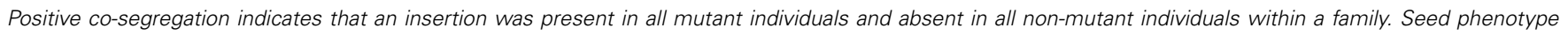
abbreviations: embryo lethal (emb), empty pericarp (ep), small kernel (smk), defective kernel (dek).

using custom, Java-based programs (McCarty et al., 2013b). During this process, each sequence is anchored to a specific genomic location and assigned a unique identifier. Numbers of reads at each map location are tabulated in sortable tables that are analyzed for co-segregation of a particular insertion position with a phenotype-of-interest. All sequencing reads obtained in pool \#1, for example, represent Mu-flanking sequences from family \#1 (see Figure 2). Where those same reads appear in pools A through L, they correspond to individual plants in family \#1 that each carry the $\mathrm{Mu}$ insertions indicated.

To further test sequencing results from the forward-genetic $\mathrm{Mu}$-seq grid, selected insertions were examined by PCR using DNA from individual leaf samples (family UFMu-03236, Figure 2). Primers were designed to amplify DNA flanking putative insertion sites and used together with a Mu-TIR-specific primer to amplify products if $\mathrm{Mu}$ insertions were present at the predicted location. In each of the instances tested, PCR and sequencing results agreed (Figure 2), demonstrating the accuracy and reliability of the approach.

For results to demonstrate a "positive co-segregation," an exact correspondence was required between the presence or absence of a particular insertion and the presence or absence of a given phenotype. Such co-segregation was observed for seven of the twelve families tested. Another family showed close, but imperfect, linkage between an insertion and a phenotype. Further analysis of this family showed one individual that did not produce mutant seeds despite carrying an insertion that otherwise co-segregated with this phenotype (in family UFMu-01057, pool 8). In this case, the absence of tight linkage (and thus negation of the candidate gene) was confirmed by analysis of progeny in a larger segregating family (Supplemental Figure 1), further validating the efficacy and accuracy of forward-genetic Mu-seq.

\section{IDENTIFICATION OF PUTATIVE CAUSAL GENE MUTATIONS}

The seven insertion sites that co-segregated perfectly with kernel phenotypes were analyzed for proximity to annotated maize genes (B73 reference v2, filtered gene set). In each instance, the $\mathrm{Mu}$ insertion was in or near the coding sequence associated with a gene (Table 2, Figure 3). Of these, four showed embryo-lethal phenotypes that co-segregated with $\mathrm{Mu}$ insertions in specific genes: one coding for the Whirlyl transcription factor, one for a putative mitochondrial transcription termination factor, one for an unknown protein, and one for a putative pentatricopeptide repeat family protein (PPR). Two of the empty-pericarp phenotypes co-segregated with insertions in different, putative PPR genes. Finally, a small-kernel phenotype co-segregated with an insertion in a predicted RNA-binding, $\mathrm{KH}$-domain-containing gene. Six of the seven insertions are in putative exons, with the only exception being an insertion just downstream of the $5^{\prime}$-UTR in the first intron of an RNA-binding $\mathrm{KH}$-domain-containing gene (Table 2, Figure 3).

\section{VALIDATION OF CO-SEGREGATION RESULTS}

Locus-specific PCR was used to further validate positive cosegregations obtained from grid sequencing. Individuals from larger F2 families (of 20 or more individuals) segregating for the phenotypes-of-interest were scored as mutant or non-mutant and genotyped. Gene-specific primers flanking the insertion site were used to test for the presence of a wildtype copy of the gene, and one gene-specific primer, together with a Mu-TIR-specific primer were used to test for the presence of an insertion in the gene. Cosegregation was confirmed in all six instances where $\mathrm{Mu}$-insertion sites were amenable to PCR (Table 3, Supplemental Figure 1). Attempts to amplify the 7th putative causal insertion (that in the RNA-binding $\mathrm{KH}$-domain-containing gene) using multiple primer combinations were unsuccessful. Map distances were 
Table 2 | Putative causal genes identified by forward-genetic Mu-seq.

\begin{tabular}{|c|c|c|c|c|}
\hline Family & Gene & Putative annotation & Insertion location & Position \\
\hline UFMu-04889 & GRMZM2G061542 & Mitochondrial transcription termination factor & Chr 1-191,063,545 & Exon $1 \mathrm{CDS}$ \\
\hline UFMu-00117 & GRMZM2G308189 & Pentatricopeptide repeat (PPR-1) & Chr 5-181,583,967 & Exon $1 \mathrm{CDS}$ \\
\hline UFMu-03236 & GRMZM2G069078 & Pentatricopeptide repeat (PPR-2) & Chr 8-170,866,001 & Exon $1 \mathrm{CDS}$ \\
\hline
\end{tabular}

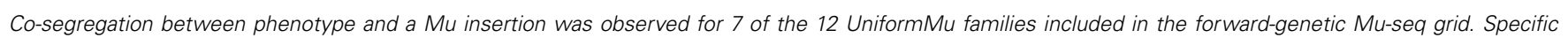

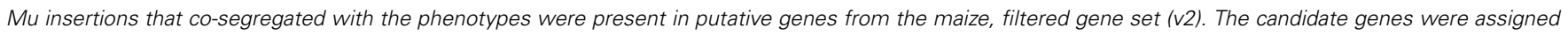

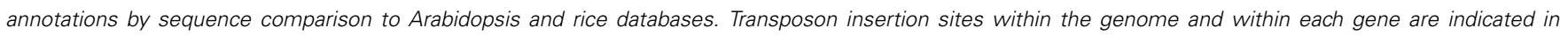
columns 4 and 5. Phenotypes from the other 5 families included in the grid did not show a Mu insertion co-segregating.

calculated with $95 \%$ confidence based on the total number of individuals genotyped, including both PCR- and sequence-based approaches. The formula used for calculating map distances was: distance in centimorgans $=\left(1-0.05^{\frac{1}{N}}\right) * 100$, where $N$ is the number of individuals genotyped.

Additional mutant alleles for each of the seven candidate genes were sought by searching the UniformMu database (available at MaizeGDB.org). Second mutant alleles with insertions in different sites were available for six of the seven target genes (Figure 3; Table 4). For each of those six genes, a UniformMu line was selected that carried a second mutant allele. The lines chosen were prioritized for insertions in coding vs. non-coding sequences. These UniformMu lines were grown, self pollinated, and ears were examined for seed phenotypes. Locus-specific PCR was used to test for specific insertions and for their co-segregation with identified seed phenotypes (Table 4). Additional alleles from the Whirlyl transcription factor and two of the PPR genes showed co-segregation with like-phenotypes, confirming causality for mutations in these genes and the associated phenotypes. The additional allele in the mitochondrial transcription termination factor was not amplified by PCR, so co-segregation with the expected phenotype could not be confirmed in this instance. Insertions in the unknown protein-coding gene and the RNAbinding $\mathrm{KH}$ domain-containing genes were identified, but visible phenotypes were not evident (Table 4).

Mutations associated with this sample of kernel phenotypes predominated in genes predicted to mediate nuclear control over organellar-gene processing, thus highlighting the importance of this process during seed development. Transit-peptide analysis indicated that four of the predicted proteins are targeted to mitochondria and one to plastids (Table 5). Notably, each of the three putative PPR genes are predicted to encode mitochondrial-targeted proteins. Despite this similarity, all are linked with distinctive kernel phenotypes, ranging from empty pericarp to embryo lethality (Figure 3).

\section{DISCUSSION}

Here we present a new set of putative causal genes underlying kernel phenotypes in maize and introduce the strategy and protocol used to obtain them. To achieve reliable, efficient, co-segregation analyses of segregating mutant families, we developed "forwardgenetic Mu-seq." The speed and efficacy of forward-genetic $\mathrm{Mu}$-seq were enabled by an approach that included existing technology, redesigned for high-throughput, phenotype-to-genotype analyses. This was used together with a streamlined genetic pipeline for establishing families that segregated for mutations of interest, and a gridding design for integrated analysis of genotypes and phenotypes. Candidate mutations were successfully obtained for seven of twelve maize mutants examined concurrently in a single experiment. This approach is particularly advantageous for analysis of the high-copy Mutator transposon system in maize, and may be adapted to other multi-copy transposon systems with conserved TIR sequences. Conventional approaches for genetic analysis of Mutator lines, which may contain in excess of 100 unique transposon insertions per individual, typically entail multiple generations of backcrossing and selection to reduce the number of $\mathrm{Mu}$ elements in plants analyzed. By enabling simultaneous tracking of all insertions in a population, forward-genetic $\mathrm{Mu}$-seq allows testing of correlations between genotype and phenotype without extensive backcrossing. Another key feature of this protocol is that genetic analyses of multiple insertions can be performed without needing a specific genotyping assay for each mutation. The development and validation of gene-specific PCR assays for genotyping is frequently time-consuming and too-often frustrating. Moreover, we find that a Mu-seq approach detects $\mathrm{Mu}$ insertions that are recalcitrant to classical PCR methods (Table 3; Supplemental Figure 1). Relieving this constraint is especially important for emerging, large-scale, functional genomics applications, such as testing knockouts in multiple candidate genes for QTLs that may require genotyping multiple insertions of interest in many hundreds of individuals. Also, forward-genetics $\mathrm{Mu}-\mathrm{seq}$ will become progressively more cost-effective with continuing advances in sequencing technology.

Forward-genetics $\mathrm{Mu}$-seq is particularly well-suited to cosegregation analyses in studies of recessive seed mutants that can be observed on mature, self-pollinated ears. Presence of such kernel mutants on an ear indicate a heterozygous parent carrying a single copy of the mutant gene (as two copies yield seed lethality, making recovery of homozygous plants impossible), whereas lack of such kernels indicate a wildtype parent. Such plants (or progeny from a back-cross such as shown in 
Whirly-like transcription factor

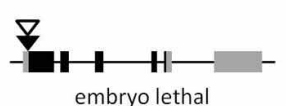

Mitochondrial transcription termination factor
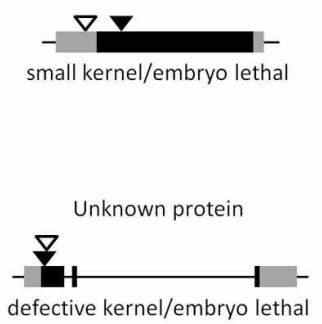

Pentatricopeptide Repeat Protein

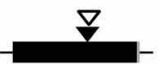

small kernel/embryo lethal

Pentatricopeptide Repeat Protein

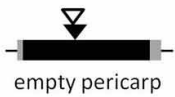

Pentatricopeptide Repeat Protein

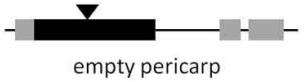

empty pericarp

RNA-binding $\mathrm{KH}$-domain containing protein

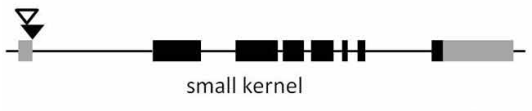

$1.5 \mathrm{~kb}$
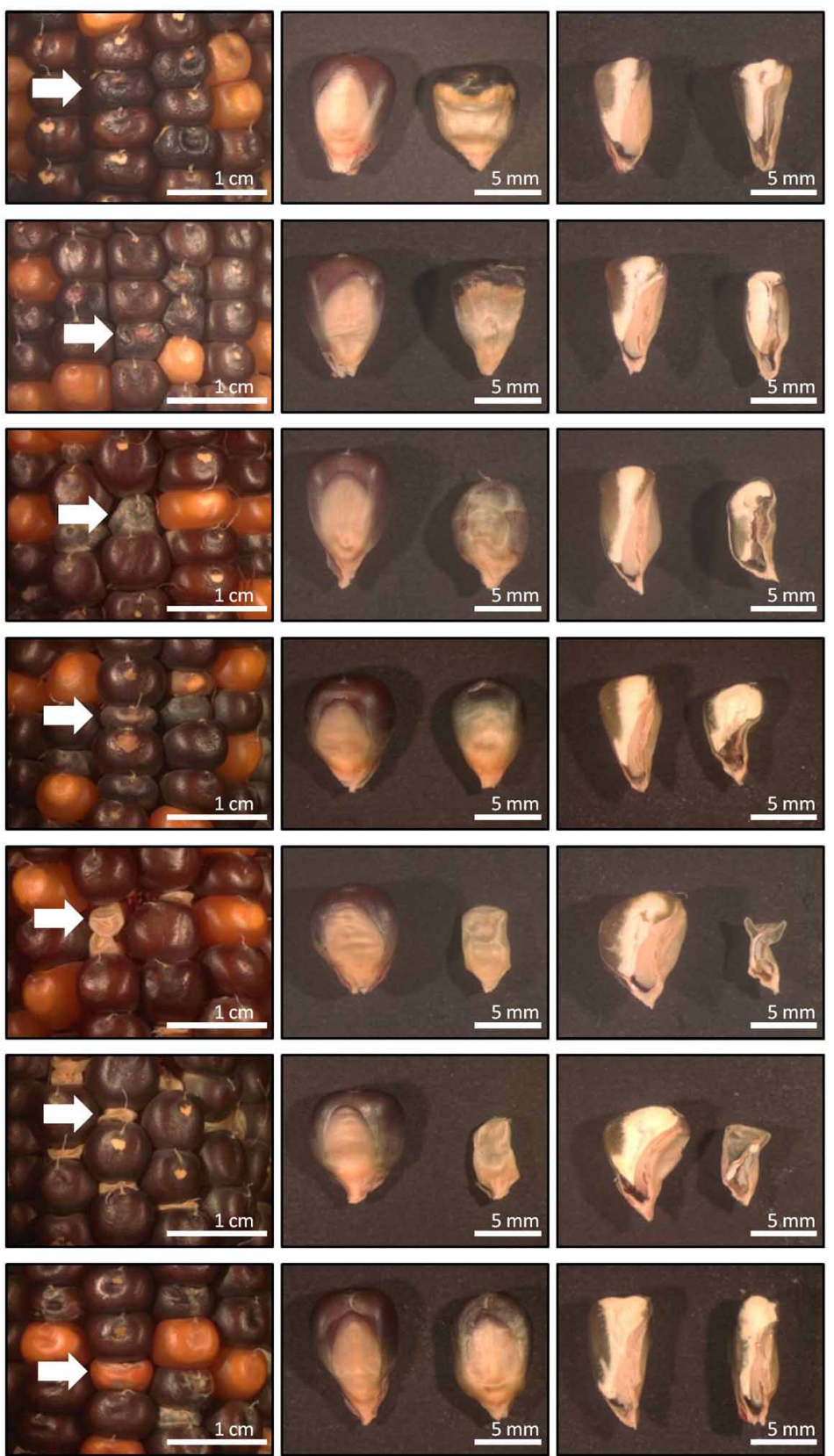

FIGURE 3 | Gene mutations that co-segregate with seed phenotypes. The seven, positive, co-segregation results from the forward-genetics Mu-seq grid corresponded to insertions in seven maize genes. The genes are diagrammed on the left, with $\mathrm{Mu}$ insertion sites identified in the sequencing grid indicated by black triangles, coding sequence by black bars, and untranslated regions by gray bars. Black-bordered, open triangles indicate positions of additional alleles available in other UniformMu lines. Six of the seven insertion sites were in exons, with the exception being an insertion in the first intron of a predicted RNA-binding protein that co-segregated with a defective kernel phenotype (bottom panels). The phenotypes that co-segregate with each insertion are represented in the images to the right, showing on-ear appearance, embryo faces of mature kernels, and vertical, saggital sections of mature kernels (with normal seeds to the left and mutant seeds to the right). Representative normal and mutant kernels were selected for imaging. White arrows indicate mutant kernels.
Figure 1A) are ideal for constructing forward-genetic Mu-seq grids since presence or absence of a given $\mathrm{Mu}$ insertion can be readily scored from sequence data to test for co-segregation. Nonlethal can also be pursued using this approach. In such instances, it would be ideal to grow F2 progeny to observe phenotypes prior to gridding, allowing heterozygous, homozygous, and wildtype parents to be scored (similar to scoring an ear for a segregating seed phenotype). In some instances it may even be possible to distinguish homozygous from heterozygous individuals in a sequencing grid. Theoretically, insertions should yield twice the 
number of sequencing reads when homozygous vs. heterozygous. While there is a high degree of variability in read number from insertion to insertion, we have observed good consistency in read number for a given insertion from sample to sample (see Figure 2; McCarty et al., 2013b). We suggest that the variability occurs because each insertion is amplified to different, yet often-repeatable degrees during construction of sequencing libraries depending on the insertion locale and flanking-sequence composition. At present, however, variability in read number precludes an effective, repeatable delineation of homozygous and heterozygous insertions.

Strong candidate genes are identified by the relationships between $\mathrm{Mu}$ insertions and closely-linked phenotypes reported

Table 3 | Genetic analyses of progeny.

\begin{tabular}{|c|c|c|c|c|}
\hline $\begin{array}{l}\text { Putative } \\
\text { annotation }\end{array}$ & Phenotype & $\begin{array}{l}\text { Positive co- } \\
\text { segregation? }\end{array}$ & $\begin{array}{l}\text { Individuals } \\
\text { genotyped }\end{array}$ & $\begin{array}{l}\text { Map } \\
\text { distance }\end{array}$ \\
\hline $\begin{array}{l}\text { Whirly1 transcription } \\
\text { Factor }\end{array}$ & emb & Yes & $21 / 21$ & $13.3 \mathrm{cM}$ \\
\hline $\begin{array}{l}\text { Mitochondrial } \\
\text { transcription } \\
\text { termination factor }\end{array}$ & smk/emb & Yes & $28 / 28$ & $10.1 \mathrm{cM}$ \\
\hline Unknown protein & dek/emb & Yes & $35 / 35$ & $8 \mathrm{cM}$ \\
\hline $\begin{array}{l}\text { Pentatricopeptide } \\
\text { repeat (PPR-1) }\end{array}$ & smk/emb & Yes & $21 / 21$ & $13.3 \mathrm{cM}$ \\
\hline $\begin{array}{l}\text { Pentatricopeptide } \\
\text { repeat (PPR-2) }\end{array}$ & ep & Yes & $35 / 35$ & $8.2 \mathrm{cM}$ \\
\hline $\begin{array}{l}\text { Pentatricopeptide } \\
\text { repeat (PPR-3) }\end{array}$ & ep & Yes & $29 / 29$ & $9.9 \mathrm{cM}$ \\
\hline $\begin{array}{l}\text { RNA-binding } \mathrm{KH} \\
\text { domain-containing } \\
\text { protein }\end{array}$ & smk & $\begin{array}{l}\text { PCR } \\
\text { recalcitrant }\end{array}$ & $12 / 12$ & $22.1 \mathrm{cM}$ \\
\hline
\end{tabular}

Individual PCR used to further validate co-segregation of phenotypes with insertions identified in the forward-genetics Mu-seq grid within segregating F2 families. Positive co-segregation indicates that the putative causal insertions showed perfect co-segregation in all individuals tested. Map distances were estimated based on the number of individuals genotyped either by sequencing or PCR, and is reported at a 95\% confidence level. Seed phenotype abbreviations: embryo lethal (emb), empty pericarp (ep), small kernel (smk), and defective kernel (dek). here. Second alleles or complementation experiments are needed for confirmation. Analysis of additional mutant alleles confirmed associations between mutations in the Whirlyl transcription factor and two of the PPR genes with seed lethal phenotypes (Table 4). Causality is yet to be determined between the identified $\mathrm{Mu}$ insertions and the phenotypes for the other four candidate genes. Alternative UniformMu alleles were not available for the third PPR gene. In the case of the mitochondrial transcription factor gene, the second allele segregated for the expected embryo lethal phenotype, but we were unable to amplify the target insertion using PCR. For the RNA-binding $\mathrm{KH}$ domain-containing gene and the Unknown protein-coding gene, second alleles did not produce see phenotypes (Table 4), despite being detected by PCR. The initially-identified insertions may be linked with the causal mutation, but not directly responsible for the phenotypes. Alternatively, insertion positions at different sites in a gene can

Table 5 | Predicted localizations of proteins encoded by the putative, causal genes carrying Mu insertions.

\begin{tabular}{|c|c|c|c|}
\hline Putative annotation & $\begin{array}{l}\text { Predicted } \\
\text { localization }\end{array}$ & $\begin{array}{l}\text { TargetP } \\
\text { score }\end{array}$ & Phenotype \\
\hline Whirly1 transcription factor & Plastid & 0.874 & emb \\
\hline $\begin{array}{l}\text { Mitochondrial transcription } \\
\text { termination factor }\end{array}$ & Mitochondria & 0.912 & smk/emb \\
\hline Unknown protein & $?$ & & dek/emb \\
\hline $\begin{array}{l}\text { Pentatricopeptide repeat } \\
\text { (PPR-1) }\end{array}$ & Mitochondria & 0.720 & smk/emb \\
\hline $\begin{array}{l}\text { Pentatricopeptide repeat } \\
\text { (PPR-2) }\end{array}$ & Mitochondira & 0.857 & ep \\
\hline $\begin{array}{l}\text { Pentatricopeptide repeat } \\
\text { (PPR-3) }\end{array}$ & Mitochondria & 0.832 & ep \\
\hline $\begin{array}{l}\text { RNA-binding } \mathrm{KH} \\
\text { domain-containing protein }\end{array}$ & $?$ & & smk \\
\hline
\end{tabular}

Signal-peptide analysis for the seven, putative, causal genes for seed phenotypes were examined using the web-based TargetP utility. Scores represent confidence of the predicted localization. Values over 0.7 were considered strongly predictive. A "?" indicates no localization prediction obtained. Phenotype abbreviations: embryo lethal (emb), small kernel (smk), defective kernel (dek), empty pericarp (ep).

Table 4 | Genetic analyses of additional alleles from UniformMu.

\begin{tabular}{|c|c|c|c|c|}
\hline Putative annotation & UniformMu family & Position & Phenotype & Co-segregates? \\
\hline Whirly 1 transcription factor & UFMu-06220 & Exon 1 UTR & emb & Yes \\
\hline Mitochondrial transcription termination factor & UFMu-08145 & Exon 1 UTR & smk/emb & PCR recalcitrant \\
\hline Unknown protein & UFMu-01783 & Exon $1 \mathrm{CDS}$ & none & N/A \\
\hline Pentatricopeptide repeat (PPR-1) & UFMu-03453 & Exon 1 CDS & smk/emb & Yes \\
\hline Pentatricopeptide repeat (PPR-2) & UFMu-03459 & Exon $1 \mathrm{CDS}$ & ep & Yes \\
\hline Pentatricopeptide repeat (PPR-3) & None available & N/A & N/A & N/A \\
\hline RNA-binding $\mathrm{KH}$ domain-containing protein & UFMu-06477 & Exon 1 UTR & none & N/A \\
\hline
\end{tabular}

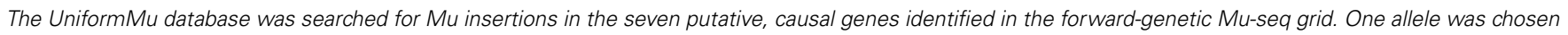

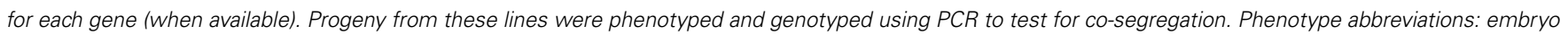
lethal (emb), small kernel (smk), defective kernel (dek), empty pericarp (ep). 
have contrasting effects on gene transcript accumulation (Greene et al., 1994; Girard and Freeling, 2000; Settles et al., 2001; Cui et al., 2003). In particular, we have found that insertions in $5^{\prime}$ UTRs are often ineffective in conferring a dysfunctional mutation (unpublished results). Such insertions can sometimes be spliced as introns or ignored in untranslated regions.

Mutant alleles for one of the seven candidate genes have been previously described, confirming that the insertion identified in the present study was indeed causal. Zhang et al. (2013) showed that mutations to the Whirly1 transcription factor (allelic to the one revealed here) lead to embryo-defective phenotypes. Interestingly, Prikyryl et al. (2008) had previously described two mutations in the same Whirlyl transcription factor that conferred albino-seedling phenotypes, but not defective embryos. Background effects can markedly alter expression of phenotypes in maize (Lee et al., 1994; Hunter et al., 2012), and indeed, Zhang et al. (2013) demonstrated this by introgressing UniformMu alleles of the Whirly1 transcription factor into non-W22 inbreds, where albino seedlings were observed.

One particularly striking finding of the forward-genetic $\mathrm{Mu}$ seq grid analyzed here was the predominance of mutants in genes coding for predicted organellar-targeted proteins. The forward-genetic Mu-seq approach can be particularly useful when genotype-to-phenotype investigations focus on dissecting developmental pathways. Selecting like-phenotypes from a collection of mutants and genotyping them using this strategy enables targeted analysis of whichever pathways affect the phenotype of interest. The grid sequenced here was directed toward seed phenotypes, and results indicate a pivotal role for mitochondrial RNA-editing in kernel development. Four of the seven candidate genes are predicted to modulate that process at some level (Table 5). This finding is analogous to that of a growing number of studies pointing to prominent roles of organellar function in embryogenesis and seed development (McElver et al., 2001; Schmitz-Linneweber and Small, 2008; Myouga et al., 2010; Bryant et al., 2011; Steinnebrunner et al., 2011; Holdorf et al., 2012; Benz et al., 2013).

Pentatricopeptide repeat-containing proteins, in particular, have been implicated in seed-development phenotypes of both Arabidopsis (Tzafrir et al., 2003; Lurin et al., 2004; Tzafrir et al., 2004; Cushing et al., 2005; Falcon de Longevialle et al., 2007; Lu et al., 2011) and maize (Gutiérrez-Marcos et al., 2007; Manavski et al., 2012; Sosso et al., 2012a,b; Liu et al., 2013). In subsequent, forward-genetic Mu-seq grids that targeted defectivekernel mutants, we have identified an additional 12 insertions in PPR-containing genes as putative, causal mutations (unpublished data). Collectively, these mutations in 15 PPR-containing genes represent approximately half of the total, putative, causal-genes we have identified in our research on seed mutants using this approach. The outcome is clearly consistent with the importance of PPR proteins in maize kernel development.

The number of unrecovered mutations in the forward-genetics $\mathrm{Mu}$-seq described in the present paper was higher than initially predicted, with five of twelve mutants not showing a co-segregating gene mutation. One of the possible explanations is that some of the mutations are not caused by $\mathrm{Mu}$ transposons. Deletion alleles have been obtained from Mutator-based resource populations, including UniformMu (Robertson et al., 1994; Bortiri et al., 2006), though their prominence has not been thoroughly examined. Other possibilities may reflect limitations of our present approach. Mu-seq libraries are currently prepared using primers that bind to the conserved TIRs of the canonical $\mathrm{Mu}$ transposons, Mul through $\mathrm{Mu} 9$ and $\mathrm{Mu} 13$ through $\mathrm{Mu} 19$ (Dietrich et al., 2002; Tan et al., 2011; McCarty et al., 2013b). The Mutator family includes more diverse members (Mu10, Mu11, and Mu12) that are known to be active at some level Mutatorderived stocks (Dietrich et al., 2002). Molecular tools designed to recognize the canonical $\mathrm{Mu}$ transposons do not recognize the TIRs from these more diverse Mu transposons. Some of the unrecovered mutants from this grid may be caused by non-canonical elements. Another potential limitation may lie in the current, data-analysis pipeline. Mu-flanking sequences that do not map to the B73 filtered gene set are excluded from further analysis and are not used for comparison to phenotypes for co-segregation analysis. However, as noted above, this has been less than 3\% of insertions examined thus far. We are continually improving our ability to detect $\mathrm{Mu}$ insertion sites and are pursuing non-tractable mutants to understand their extent and role in the UniformMu population. Forward-genetic Mu-seq nonetheless offers a successful means of capturing putative causal genes for about $50 \%$ of visible mutants from the UniformMu resource. A similar level of efficacy has been evident in subsequent, forward-genetic Mu-seq grids (unpublished data).

A two-dimensional grid design (as used in the present study) would typically be the preferred strategy in forward genetic $\mathrm{Mu}-\mathrm{seq}$, because it enables a more thorough analysis than singledimension sequencing alone. Single-dimension strategies would theoretically be adequate where previous work had identified most of the new $\mathrm{Mu}$ insertions in a given line. This is the case for Uniform $\mathrm{Mu}$ material since $\mathrm{Mu}$ insertions in these families were mapped during construction of the public resource. In high-throughput analyses of such material, where speed or cost savings are paramount, co-segregation using single-dimension sequencing may be desirable. However, results will rely on causal insertions having already been assigned to a family. In the grid shown here, sequencing pools A through $\mathrm{H}$ would have identified only 6 of the 7, putative, causal insertions. This is because the 7 th had not yet been identified in the UniformMu lines tested (possibly due to limited presence among sibling material sampled at the time of resource generation), so could not be assigned to the correct family without sequencing pools 1 through 12 . While single-dimensional sequencing would have yielded good results, a two-dimensional grid design gives a greater level of confidence with little additional effort or cost (since all of the sequencing is done in a single flow cell). Our current system of 4-base barcodes enables simultaneous genotyping of up to 1024 individuals in a two-dimension, $32 \times 32$ grid. Although recovery of reads from individual insertions can vary up to 800 -fold depending on genome context and other factors that are not readily simulated (McCarty et al., 2013b), our empirical tests indicate that a single HiSeqII lane typically provides adequate coverage of grids of at least $25 \times 25$ ( 625 individuals).

Forward-genetic Mu-seq for fast, efficient genotyping of Mutator-derived maize lines vastly increases the throughput of 
genetic analyses. The small-scale study presented here highlights the power and simplicity of the technology and demonstrates the effectiveness of the strategy for dissecting specific developmental pathways. By analyzing defective kernel mutants using a forward-genetic Mu-seq strategy, a clearer picture of the genes and processes important for kernel development is emerging. Mitochondrial and plastidial gene transcription and processing, under the control of nuclear-encoded proteins, clearly play a predominant role. Here we see a prominent degree of nonredundancy for these important genes and the relative abundance of organelle-targeted proteins whose mutations affect kernel development.

\section{AUTHOR CONTRIBUTIONS}

Charles T. Hunter, Masaharu Suzuki, Donald R. McCarty, and Karen E. Koch each contributed to the experimental design and implementation of the work. Charles T. Hunter, Jonathan Saunders, Shan $\mathrm{Wu}$, and Alexander Tasi were each central to conducting the experiments and acquiring the data presented in the work. Charles T. Hunter and Karen E. Koch were principally responsible for drafting the final manuscript. All authors provided intellectual content and contributed to manuscript revisions. All authors provided final approval of the manuscript. All authors agree to be accountable for all aspects of the work, including ensuring the accuracy and integrity of the work.

\section{ACKNOWLEDGMENTS}

The authors acknowledge the funding sources for the work presented here: NSF-PGRP: 10S-1116561, NSF-PGRP: 10S-1025976, and USDA-NIFA: 2010-04228.

\section{SUPPLEMENTARY MATERIAL}

The Supplementary Material for this article can be found online at: http://www.frontiersin.org/journal/10.3389/fpls.2013.00545/ abstract

\section{Supplemental Figure 1 | Follow-up co-segregation PCR results.}

Co-segregation of phenotypes with insertions identified in the sequencing grid was tested in the following generation. Selfed ears from segregating families were examined for phenotypes, and DNA from parent plants was used for PCR to test for co-segregation. Gene-specific primers flanking the insertion site were used to test for the presence of a wildtype copy of the gene ( $F$ plus $R$ ), and one gene-specific primer along with a $\mathrm{Mu}$-TIR-specific primer were used to test for the presence of an insertion in the gene (F plus TIR6). Mutants were present as heterozygotes, so both wildtype and mutant bands were observed. The gene model shown indicates primer locations for an insertion in the unknown protein for which co-segregation of a Mu insertion with a defective kernel phenotype was tested. The Mu insertion site is indicated by a black triangle, primers by small black arrows, coding sequence by black bars, and untranslated regions by gray bars. Co-segregation between seed phenotypes and candidate Mu insertions was observed for all genes, with the exception of the putative sugar-phosphate translocator (bottom right), which showed no correlation between the presence of a defective kernel phenotype and the Mu insertion of interest (and was one off from co-segregating in the sequencing grid). A "?" represents an ear for which the phenotype was ambiguous. Seed phenotype abbreviations: embryo lethal (emb), empty pericarp (ep), small kernel (smk), defective kernel (dek).

\section{Supplemental Figure 2 | PCR primer sequences and annealing}

temperatures. Melting temperatures were estimated using the web-based tool from Integrated DNA Technologies (idtdna.com), with all parameters set at default. a Primer was used in genotyping to confirm co-segregation in larger F2 families. ${ }^{b}$ Primer was used in Pool 7 validation experiments. ${ }^{c}$ Primer was used in sequencing library preparation.

Supplemental Table 1 | List of Mu insertion locations identified. Insertion positions are presented organized by family of origin. Normalized read counts are shown for pools $A$ through $L$, corresponding to the 12 plants genotyped for each family. Cells highlighted blue indicate presence of a given insertion (with 50 or more reads detected), and cells highlighted yellow indicate absence of a given insertion (with less than 50 reads detected).

\section{REFERENCES}

Ahern, K. R., Deewatthanawonga, P., Schares, J., Muszynski, M., Weeks, R., Vollbrecht, E., et al. (2009). Regional mutagenesis using dissociation in maize. Methods 49, 248-254. doi: 10.1016/j.ymeth.2009.04.009

Alonso, J. M., Stepanova, A. N., Leisse, T. J., Kim, C. J., Chen, H., Shinn, P., et al. (2003). Genome-wide insertional mutagenesis of Arabidopsis thaliana. Science 301, 653-657. doi: 10.1126/science.1086391

Altschul, S. F., Gish, W., Miller, W., Myers, E. W., and Lipman, D. J. (1990). Basic local alignment search tool. J. Mol. Biol. 215, 403-410.

Andersen, M. N., Asch, F., Wu, Y., Jensen, C. R., Næsted, H., Mogensen, V. O., et al. (2002). Soluble invertase expression is an early target of drought stress during the critical, abortion-sensitive phase of young ovary development in maize. Plant Physiol. 130, 591-604. doi: 10.1104/pp.005637

Bensen, R. J., Johal, G. S., Crane, V. C., Tossberg, J. T., Schnable, P. S., Meeley, R. B., et al. (1995). Cloning and characterization of the maize Anl gene. Plant Cell 7, 75-84.

Benz, M., Soll, J., and Ankele, E. (2013). Arabidopsis thaliana Oxa proteins locate to mitochondria and fulfill essential roles during embryo development. Planta 237, 573-588. doi: 10.1007/s00425-012-1793-9

Bortiri, E., Chuck, G., Volbrecht, E., Rocheford, T., Martienssen, R., and Hake, S. (2006). ramosa2 encodes a LATERAL ORGAN BOUNDARY domain that determines the fate of stem cells in branch meristems of maize. Plant Cell 18, 574-585. doi: 10.1105/tpc.105.039032

Bryant, N., Lloyd, J., Sweeney, C., Myouga, F., and Meinke, D. (2011). Identification of nuclear genes encoding chloroplast-localized proteins required for embryo development in Arabidopsis. Plant Physiol. 155, 1678-1689. doi: 10.1104/pp.110.168120

Cowperthwaite, M., Park, W., Xu, Z., Yan, X., Maurais, S. C., and Dooner, H. K. (2002). Use of the transposon $A c$ as a gene-searching engine in the maize genome. Plant Cell 14, 713-726. doi: 10.1105/tpc.010468

Cui, X., Hsia, A.-P., Liu, F., Ashlock, D. A., Wise, R. P., and Schnable, P. S. (2003). Alternative transcription initiation sites and polyadenylation sites are recruited during $M u$ suppression at the rf2a locus of maize. Genetics 163, 685-698.

Cushing, D. A., Forsthoefel, N. R., Gestaut, D. R., and Vernon, D. M. (2005). Arabidopsis emb175 and other ppr knockout mutants reveal essential roles for pentatricopeptide repeat (PPR) proteins in plant embryogenesis. Planta 221, 424-436. doi: 10.1007/s00425-004-1452-x

Dietrich, C. R., Cui, F., Packila, M. L., Li, J., Ashlock, D. A., Nikolau, B. J., et al (2002). Maize $\mathrm{Mu}$ transposons are targeted to the $5^{\prime}$ untranslated region of the gl8 gene and sequences flanking Mu target-site duplications exhibit nonrandom nucleotide composition throughout the genome. Genetics 160, 697-716.

Emanuelsson, O., Brunak, S., von Heijne, G., and Nielson, H. (2007). Locating proteins in the cell using TargetP, SignalP, and related tools. Nat. Protocols 2, 953-971. doi: 10.1038/nprot.2007.131

Emanuelsson, O., Nielson, H., Brunak, S., and von Heijne, G. (2000). Predicting subcellular localization of proteins based on the $\mathrm{N}$-terminal amino acid sequence. J. Mol. Biol. 300, 1005-1016. doi: 10.1006/jmbi.2000.3903

Falcon de Longevialle, A., Meyer, E. H., Andre, C., Taylor, N. L., Lurin, C., Millar, A. H., et al. (2007). The pentatricopeptide repeat gene OTP43 is required for trans-splicing of the mitochondrial nad 1 intron 1 in Arabidopsis thaliana. Plant Cell 19, 3256-3265. doi: 10.1105/tpc.107.054841 
Galbiati, M., Moreno, M. A., Nadzan, G., Zourelidou, M., and Dellaporta, S. L. (2000). Large-scale T-DNA mutagenesis in Arabidopsis for functional genomic analysis. Funct. Integr. Genomics 1, 25-34. doi: 10.1007/s101420000007

Girard, L., and Freeling, M. (2000). Mutator-suppressible alleles of rough sheath1 and liguleless 3 in maize reveal multiple mechanisms for suppression. Genetics 154, 437-446.

Greene, B., Walko, R., and Hake, S. (1994). Mutator insertions in an intron of the maize knotted1 gene result in dominant suppressible mutations. Genetics 138, 1275-1285.

Gutiérrez-Marcos, J. F., Dal Pra, M., Giulini, A., Costa, L. M., Gavazzi, G., Cordelier, S., et al. (2007). empty pericarp4 encodes a mitochondrion-targeted pentatricopeptide repeat protein necessary for seed development and plant growth in maize. Plant Cell 19, 196-210. doi: 10.1105/tpc.105.039594

Holdorf, M. M., Owen, H. A., Lieber, S. R., Yuan, L., Adams, N., Dabney-Smith, C., et al. (2012). Arabidopsis ETHE1 encodes a sulfer dioxygenase that is essential for embryo and endosperm development. Plant Physiol. 160, 226-236. doi: 10.1104/pp.112.201855

Hsing, Y. I., Chern, C. G., Fan, M. J., Chen, K. T., Lo, S. F., Lee, K. W., et al. (2007). A rice gene activiation/knockout mutant resource for high throughput functional genomics. Plant Mol. Biol. 63, 351-364. doi: 10.1007/s11103-006-9093-Z

Hunter, C. T., Kirienko, D. H., Sylvester, A. W., Peter, G. F., McCarty, D. R., and Koch, K. E. (2012). Cellulose Synthase-Like D1 is integral to normal cell division, expansion, and leaf development in leaves. Plant Physiol. 158, 708-724. doi: 10.1104/pp.111.188466

Jeong, D. H., An, S., Park, S., Kang, H. G., Park, G. G., Kim, S. R., et al. (2006) Generation of a flanking sequence-tag database for activation-tagging lines in japonica rice. Plant J. 45, 123-132. doi: 10.1111/j.1365-313X.2005.02610.x

Klopfenstein, T. J., Erickson, G. E., and Berger, L. L. (2012). Maize is a critically important source of food, feed, energy and forage in the USA. Field Crops Res. 153, 5-11. doi: 10.1016/j.fcr.2012.11.006

Koch, K. E. (2004). Sucrose metabolism: regulatory mechanisms and pivotal roles in sugar sensing and plant development. Curr. Opin. Plant Biol. 7, 235-246. doi: 10.1016/j.pbi.2004.03.014

Krishnan, A., Guiderdoni, E., An, G., Hsing, Y. C., Han, C., Lee, M. C., et al. (2009). Mutant resources in rice for functional genomics of the grasses. Plant Physiol. 149, 165-170. doi: 10.1104/pp.108.128918

Kuromori, T., Hirayama, T., Kiyosue, Y., Takabe, H., Mizukado, S., Sakurai, T., et al. (2004). A collection of 11,800 single-copy Ds transposon insertion lines in Arabidopsis. Plant J. 37, 897-905. doi: 10.1111/j.1365.313X.2004.02009.x

Lee, I., Michaels, S. D., Masshardt, A. S., and Amasino, R. M. (1994). The lateflowering phenotype of FRIGIDA and mutations in LUMINIDEPENDENS is suppressed in the Landsberg erecta strain of Arabidopsis. Plant J. 6, 903-909. doi: 10.1046/j.1365-313X.1994.6060903.x

Liu, Y.-J., Xiu, Z.-H., Meeley, R., and Tan, B.-C. (2013). Empty Pericarp5 endodes a pentatricopeptide repeat protein that is required for mitochondrial RNA editing and seed development in maize. Plant Cell 25, 868-883. doi: 10.1105/tpc.112.106781

Lu, Y., Li, C., Wang, H., Chen, H., Berg, H., and Xia, Y. (2011). AtPPR2, an Arabidopsis pentatricopeptide repeat protein, binds to plastid 23S rRNA and plays an important role in the first mitotic division during gametogenesis and in cell proliferation during embryogenesis. Plant J. 67, 13-25. doi: 10.1111/j.1365313X.2011.04569.x

Lurin, C., Andre, C., Aubourg, S., Bellaoui, M., Bitton, F., Bruyere, C., et al. (2004). Genome-wide analysis of Arabidopsis pentatricopeptide repeat proteins reveals their essential role in organelle biogenesis. Plant Cell 16, 2089-2103. doi: 10.1105/tpc.104.022236

Manavski, N., Guyon, V., Meurer, J., Wienand, U., and Brettschneider, R. (2012). An essential pentatricopeptide repeat protein facilitates $5^{\prime}$ maturation and translation initiation of rps3 mRNA in maize mitochondria. Plant Cell 24, 3087-3105. doi: $10.1105 /$ tpc. 112.099051

May, B. P., Liu, H., Vollbrecht, E., Senior, L., Rabinowicz, P. D., Roh, D., et al. (2003). Maize-targeted mutagenesis: a knockout resource for maize. Proc. Natl. Acad. Sci. U.S.A. 101, 14349-14354.

McCarty, D. R. (1995). Genetic control and integration of maturation and germination pathways in seed development. Ann. Rev. Plant Biol. 46, 71-93. doi: 10.1146/annurev.pp.46.060195.000443

McCarty, D. R., Hattori, T., Carson, C. B., Vasil, V., Lazar, M., and Vasil, I. K. (1991). TheViviparous-1 developmental gene of maize encodes a novel transcriptional activator. Cell 66, 895-905. doi: 10.1016/0092-8674(91)90436-3
McCarty, D. R., Settles, A. M., Suzuki, M., Tan, B. C., Latshaw, S., Porch, T., et al. (2005). Steady-state transposon mutagenesis in inbred maize. Plant J. 44, 52-61. doi: 10.1111/j.1365-313X.2005.02509.x

McCarty, D. R., Suzuki, M., Hunter, C., and Koch, K. E. (2013a). "Genetic and molecular analysis of UniformMu transposon insertion lines," in Methods in Molecular Biology: Plant Transposable Elements, ed T. Peterson (New York, NY: Springer), 157-166. doi: 10.1007/978-1-62703-568-2_11

McCarty, D. R., Latshaw, S., Wu, S., Suzuki, M., Hunter, C. T., Avigne, W. T., et al. (2013b). Mu-seq: sequence-based mapping and identification of transposon induced mutations. PLoS ONE 8:e77172. doi: 10.1371/journal.pone.0077172

McElver, J., Tzafrir, I., Aux, G., Rogers, R., Ashby, C., and Smith, K. (2001). Insertional mutagenesis of genes required for seed development in Arabidopsis thaliana. Genetics 159, 1751-1763.

Meeley, R. B., and Briggs, S. P. (1995). Reverse genetics for maize. Maize Genet. Coop. Newsl. 69, 67-82.

Miyao, A., Iwasaki, Y., Kitano, H., Itoh, J. I., Maekawa, M., Murata, K., et al. (2007) A large-scale collection of phenotypic data describing an insertional mutant population to facilitate functional analysis of rice genes. Plant Mol. Biol. 63, 625-635. doi: 10.1007/s11103-006-9118-7

Miyao, A., Tanaka, K., Murata, K., Sawaki, H., Takeda, S., Abe, K., et al. (2003). Target site specificity of the Tos 17 retrotransposon shows a preference for insertion within genes and against insertion in retrotransposon-rich regions of the genome. Plant Cell 15, 1771-1780. doi: 10.1105/tpc.012559

Myouga, F., Akiyama, K., Motohashi, R., Kuromori, T., Ito, T., Iizumi, H., et al. (2010). The chloroplast function database: a large-scale collection of Arabidopsis Ds/Spm-or T-DNA-tagged homozygous lines for nuclear-encoded chloroplast proteins, and their systematic phenotype analysis. Plant J. 61, 529-542. doi: 10.1111/j.1365-313X.2009.04074.x

Parinov, S., Sevugan, M., De, Y., Yang, W.-C., Kumaran, M., and Sundaresan, V. (1999). Analysis of flanking sequences from dissociation insertion lines: a database for reverse genetics in Arabidopsis. Plant Cell 11, 2263-2270.

Prikyryl, J., Watkins, K. P., Friso, G., van Wijk, K. J., and Barkan, A. (2008). A member of the Whirly family is a multifunctional RNA- and DNA-binding protein that is essential for chloroplast biogenesis. Nucleic Acids Res. 36, 5152-5165. doi: $10.1093 / \mathrm{nar} / \mathrm{gkn} 492$

Raizada, M. N., and Walbot, V. (2000). The late developmental pattern of Mu transposon excision is conferred by a cauliflower mosaic virus 35S-driven MURA cDNA in transgenic maize. Plant Cell 12, 5-22. doi: 10.1105/tpc.12.1.5

Ray, D. K., Ramankutty, N., Mueller, N. D., West, P. C., and Foley, J. A. (2012). Recent patterns of crop yield growth and stagnation. Nature Commun. 3, 1293. doi: $10.1038 /$ ncomms 2296

Robertson, D. S. (1978). Characterization of a mutator system in maize. Mut. Res. 51, 21-28. doi: 10.1016/0027-5107(78)90004-0

Robertson, D. S., Stinard, P. S., and Maguire, M. P. (1994). Genetic evidence of Mutator-induced deletions in the short arm of chromosome 9 of maize. II. wd deletions. Genetics 136, 1143-1149.

Rosso, M. G., Li, Y., Strizhov, N., Reiss, B., Dekker, K., and Weisshaar, B. (2003). An Arabidopsis thaliana T-DNA mutagenized population (GABI-Kat) for flanking sequence tag-based reverse genetics. Plant Mol. Biol. 53, 247-259. doi: 10.1023/B:PLAN.0000009297.37235.4a

Samson, F., Brunaud, V., Balzergue, S., Dubreucq, B., Lepiniec, L., Pelletier, G., et al. (2002). FLAGdb/FST: a database of mapped flanking insertion sites (FSTs) of Arabidopsis thaliana T-DNA transformants. Nucleic Acids Res. 30, 94-97. doi: 10.1093/nar/30.1.94

Schmitz-Linneweber, C., and Small, I. (2008). Pentatricopeptide repeat proteins: a socket set for organelle gene expression. Trends Plant Sci. 13, 663-670. doi: 10.1016/j.tplants.2008.10.001

Sessions, A., Burke, E., Presting, G., Aux, G., McElver, J., Patton, D., et al. (2002). A high-throughput Arabidopsis reverse genetics system. Plant Cell 14, 2985-2994. doi: 10.1105/tpc.004630

Settles, A. M., Baron, A., Barkan, A., and Martienssen, A. (2001). Duplication and suppression of chloroplast protein translocation genes in maize. Genetics 157, 349-360.

Settles, A. M., Holding, D. R., Tan, B. C., Latshaw, S. P., Liu, J., et al. (2007). Sequence-indexed mutations in maize using the UniformMu transposontagging population. BMC Genomics 8:116. doi: 10.1186/1471-2164-8-116

Slotkin, R. K., Freeling, M., and Lisch, D. (2003). Mu killer causes the heritable inactivation of the Mutator family of transposable elements in Zea mays. Genetics $165,781-797$. 
Sosso, D., Canut, M., Gendrot, G., Dedieu, A., Chambrier, P., Barkan, A., et al. (2012a). PPR8522 encodes a chloroplast-targeted pentatricopeptide repeat protein necessary for maize embryogenesis and vegetative development. J. Exp. Bot. 63, 5843-5857. doi: 10.1093/jxb/ers232

Sosso, D., Mbelo, S., Vernoud, V., Gendrot, G., Dedieu, A., Chambrier, P., et al. (2012b). PPR2263, a DYW-subgroup pentatricopeptide repeat protein, is required for mitochondrial nad5 and cob transcript editing, mitochondrion biogenesis, and maize growth. Plant Cell 24, 676-691. doi: 10.1105/tpc. 111.091074

Steinnebrunner, I., Landschreiber, M., Krause-Buchholz, U., Teichmann, J., and Rodel, G. (2011). HCC1, the Arabidopsis homologue of the yeast mitochondrial copper chaperone SCO1, is essential for embryonic development. J. Exp. Bot. 62, 319-330. doi: 10.1093/jxb/erq269

Tan, B.-C., Chen, Z., Shen, Y., Zhang, Y., Lai, J., and Sun, S. S. M. (2011). Identification of an active new mutator transposable element in maize. G3 1, 293-302. doi: 10.1534/g3.111.000398

Tissier, A. F., Marillonnet, S., Klimyuk, V., Patel, K., Torres, M. A., Murphy, G., et al. (1999). Multiple independent defective suppressor mutator transposon insertions in Arabidopsis: a tool for functional genomics. Plant Cell 11, 1841-1852.

Tzafrir, I., Dickerman, A., Brazhnik, O., Nguyen, Q., McElver, J., Frye, C., et al. (2003). The Arabidopsis Seed Genes project. Nucleic Acids Res. 31, 90-93. doi: 10.1093/nar/gkg028

Tzafrir, I., Pena-Muralla, R., Dickerman, A., Berg, M., Rogers, R., Hutchens, S., et al. (2004). Identification of genes required for embryo development in Arabidopsis. Plant Physiol. 135, 1206-1220. doi: 10.1104/pp.104.045179

Vollbrecht, E., Duvick, J., Schares, J. P., Ahern, K. R., Deewatthanawong, P., Xu, L., et al. (2010). Genome-wide distribution of transposed Dissociation elements in maize. Plant Cell 22, 1667-1685. doi: 10.1105/tpc.109.073452

Walbot, V. (2000). Saturation mutagenesis using maize transposons. Curr. Opin. Plant Biol. 3, 103-107. doi: 10.1016/S1369-5266(99)00051-5
Woody, S. T., Austin-Phillips, S., Amasino, R. M., and Krysan, P. J. (2007). The WiscDsLox T-DNA collction: an Arabidopsis community resource generated by using an improved high-throughput T-DNA sequencing pipeline. J. Plant Res. 120, 157-165. doi: 10.1007/s10265-006-0048-x

Zhang, J., Li, C., Wu, C., Xiong, L., Chen, G., Zhang, Q., et al. (2006). RMD: a rice mutant database for functional analysis of the rice genome. Nucleic Acids Res. 34, D745-D748. doi: 10.1093/nar/gkj016

Zhang, Y.-F., Hou, M.-M., and Tan, B.-C. (2013). The requirement of WHIRLY1 for embryogenesis is dependent on genetic background in maize. PLoS ONE. 8:367369. doi: 10.1371/journal.pone.0067369

Conflict of Interest Statement: The authors declare that the research was conducted in the absence of any commercial or financial relationships that could be construed as a potential conflict of interest.

Received: 01 November 2013; paper pending published: 21 November 2013; accepted: 12 December 2013; published online: 07 January 2014.

Citation: Hunter CT, Suzuki M, Saunders J, Wu S, Tasi A, McCarty DR and Koch KE (2014) Phenotype to genotype using forward-genetic Mu-seq for identification and functional classification of maize mutants. Front. Plant Sci. 4:545. doi: 10.3389/fpls. 2013.00545

This article was submitted to Plant Genetics and Genomics, a section of the journal Frontiers in Plant Science.

Copyright (C) 2014 Hunter, Suzuki, Saunders, Wu, Tasi, McCarty and Koch. This is an open-access article distributed under the terms of the Creative Commons Attribution License (CC BY). The use, distribution or reproduction in other forums is permitted, provided the original author(s) or licensor are credited and that the original publication in this journal is cited, in accordance with accepted academic practice. No use, distribution or reproduction is permitted which does not comply with these terms. 